\title{
COOPERAÇÃO SUL-SUL EM EDUCAÇÃO E RELAÇÕES BRASIL-PALOP
}

\author{
Carlos R. S. Milani* \\ Francisco Carlos da Conceição** \\ Timóteo Saba M’Bunde
}

\begin{abstract}
Estudos sobre a cooperação internacional para o desenvolvimento (principalmente nas suas vertentes Norte-Sul e Sul-Sul) têm demonstrado que existem tipos distintos de experiências históricas que mobilizam diferentes atores domésticos e priorizam agendas temáticas com base em motivações políticas e desenhos institucionais variados. Este artigo centra-se nas estratégias do Brasil como fornecedor de cooperação no campo da educação, analisando suas tendências gerais, agendas e atores, contradições e tensões entre interesses públicos e privados. Empiricamente, o artigo também analisa essas questões a partir da atuação brasileira nos Países Africanos de Língua Oficial Portuguesa (PALOP), com foco no caso de Moçambique e considerando as percepções dos países com os quais o governo brasileiro coopera.
\end{abstract}

Palavras-chave: Cooperação internacional para o desenvolvimento. Cooperação Sul-Sul. Política externa brasileira. Relações Brasil-África. Países africanos de língua oficial portuguesa.

\section{INTRODUÇÃO}

Pesquisas sobre a cooperação internacional para o desenvolvimento Norte-Sul e Sul-Sul têm demonstrado que existem distintas experiências históricas que mobilizam atores domésticos e reforçam agendas temáticas com base em motivações das mais variadas, bem como projetos institucionais e estratégias governamentais nem sempre convergentes (Brautigam, 2011; Chatuverdi et al. 2012; Chisholm et al., 2009; Comeliau, 1991; Lancaster, 2007; Petiteville, 2001; Veen, 2011). Isso também vale para os países da Organização para a Cooperação e Desenvolvimento Económico (OCDE), entre os quais mais se avançou na institucionalização de critérios comuns e no

* Universidade do Estado do Rio de Janeiro. Instituto de Estudos Sociais e Políticos (IESP-UERJ).

Rua da Matriz, 82. Cep: 22260100. Botafogo - Rio de Janeiro - Brasil. crsmilani@iesp.uerj.br

** Universidade Eduardo Mondlane. Faculdade de Letras e Ciências Sociais. Departamento de Ciência Política e Administração Pública.

Avenida Julius Nherere. Campus Universitário. Maputo-Polana - Moçambique. Caixa-postal: 257 conceicaofra@yahoo. com.br

${ }^{* * *}$ Universidade do Estado do Rio de Janeiro. Instituto de Estudos Sociais e Políticos (IESP-UERJ).

Rua da Matriz, 82. Cep: 22260100. Botafogo - Rio de Janeiro-Brasil.timoteotisanbu@yahoo.com.br monitoramento das práticas governamentais por meio de mecanismos de revisão pelos pares. Essa diversidade de trajetórias nacionais, associada à inexistência de um regime institucionalizado de cooperação internacional para o desenvolvimento, produz obstáculos, mas também abre oportunidades em termos de criatividade política e de procedimentos de gestão flexíveis no âmbito da Cooperação Sul-Sul (CSS). Na ausência de um regime de Cooperação Internacional para o Desenvolvimento (CID), os países podem inovar quanto a regras, procedimentos e práticas; no entanto, a falta de um mínimo denominador comum pode dificultar as comparações estatísticas e a construção coletiva de normas na esfera internacional. Essa é a realidade atual das práticas Norte-Sul e Sul-Sul no campo da CID, como o impasse em torno do processo Paris-Accra-Busan tem até agora demonstrado.

No caso do Brasil, o envolvimento com a CID na qualidade de provedor não é novidade; suas primeiras experiências datam dos anos sessenta. No entanto, o financiamento governamental do Brasil e o interesse pela CID têm crescido desde a Constituição de 1988 e 
ganharam particular atenção e densidade material nos anos Lula (2003-2010). Quais são os órgãos brasileiros envolvidos na prestação de cooperação no campo da educação? Quais são as normas e os critérios adotados pelo governo? Quais são as percepções e a avaliação dos países parceiros? Essas são algumas das questões que abordamos neste artigo, com particular interesse nas ações do Brasil nos cinco países africanos de língua oficial portuguesa (PALOP), com foco em Moçambique.

\section{VISÃO GERAL DE COOPERAÇÃO PARA O DESENVOLVIMENTO IN- TERNACIONAL DO BRASIL}

De acordo com os dados oficiais publicados pelo Instituto de Pesquisa Econômica Aplicada (IPEA) e Agência Brasileira de Cooperação (ABC) $(2010,2013)$, a CID aumentou de 158 milhões de dólares em 2005 para cerca de 923 milhões de dólares em 2010. Nesse mesmo período de tempo, as despesas de cooperação técnica se multiplicaram em cinco vezes: de 11,4 milhões de dólares em 2005 para 57,7 milhões de dólares. A cooperação humanitária do com as modalidades de ambos os anos de 2009 e 2010: só em 2010, 68,1\% de toda a CID brasileira foi para a América Latina e 22,6\% para a África. No caso da América Latina, os cinco principais países parceiros constituem 80,4\% de toda a CID brasileira para a região, incluindo Haiti $(47,4 \%)$, Chile (16,3\%), Argentina $(8,6 \%)$, Peru $(4,5 \%)$ e Paraguai $(3,6 \%)$. No caso da África, os PALOP absorvem 76,5\% de toda a CID brasileira para a região: Cabo Verde é o principal com 24,4\%, seguido por GuinéBissau (21,2\%), Moçambique (13,3\%), São Tomé e Príncipe $(10,4 \%)$ e Angola, com 7,2\% (IPEA e ABC, 2013, p. 19-24). Os dados publicados pela Agência Brasileira de Cooperação (ABC) também revelam esse crescente interesse, entre os anos 2003 e 2010: o banco de dados $^{2}$ da $\mathrm{ABC}$, disponível na internet, revela que, entre 1.464 projetos concluídos entre 1999 e 2012 em outros países em desenvolvimento, 577 projetos foram desenvolvidos na América do Sul, 552 projetos foram na África, 164 no Caribe, 90 na América Central, 65 na Ásia, 15 na América do Norte (México) e 1 na Oceania (Papua Nova Guiné). Entre esses 1.464 projetos concluídos, 573 estavam em políticas sociais (saúde, cultura, esportes, desenvolvi-

Tabela 1 - A CID Brasileira em 2009 e 2010

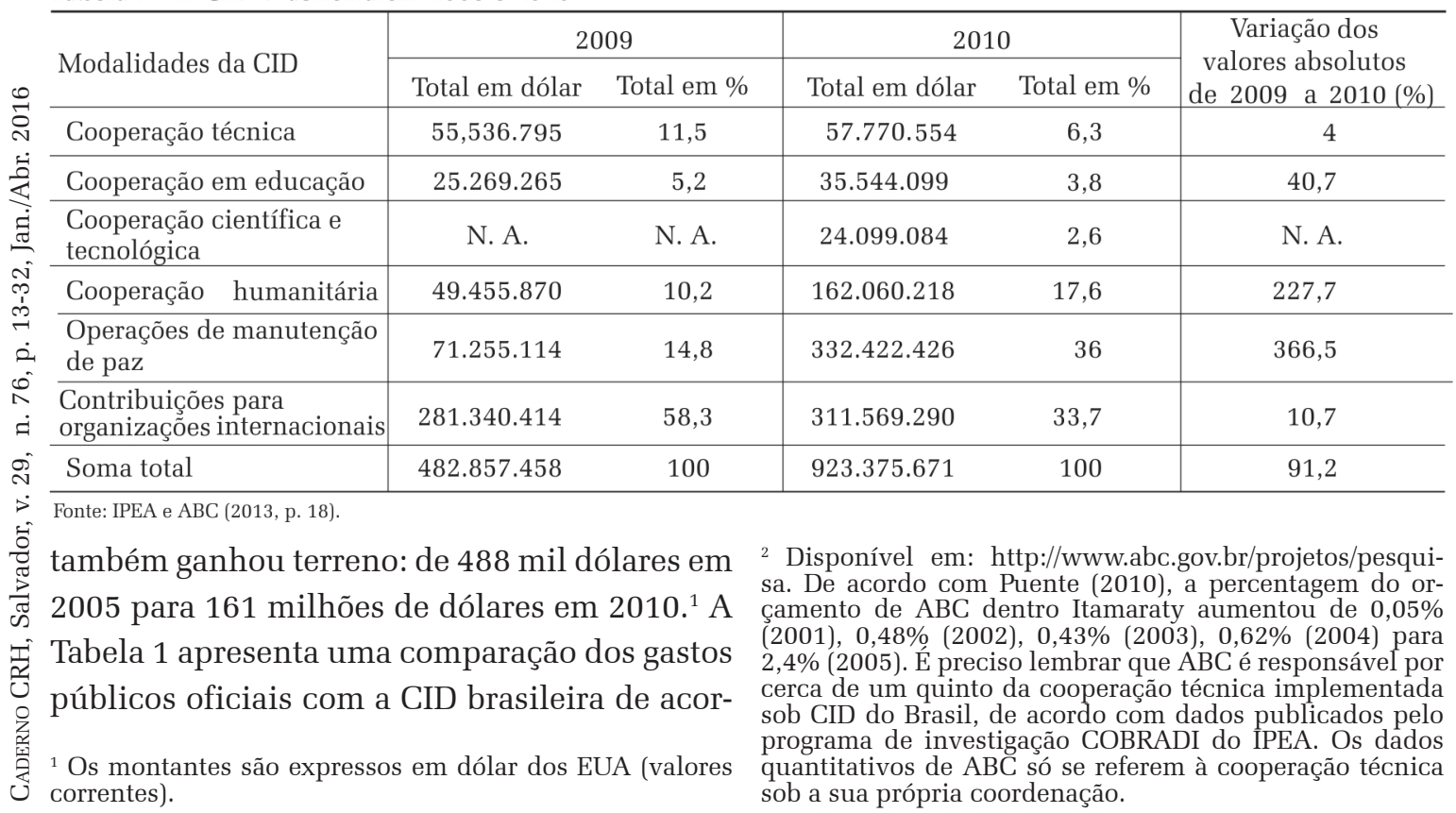


cinco PALOP (Cabo Verde, Guiné-Bissau e São Tomé e Príncipe); a contribuição total da CID do Brasil está em algum lugar entre Portugal e Coreia do Sul, ainda que extremamente baixa quando comparada com a dos países com PIB semelhante, como a França ou o Reino Unido; em Angola e Moçambique, o impacto financeiro da CID brasileira é muito limitado, quando comparado com quase todos os países selecionados. Em Angola e Moçambique, onde há investimento corporativo brasileiro (Vale do Rio Doce, Norberto Odebrecht e outras empresas de engenharia), a CID é muito presente. Além disso, o Brasil é parte de um programa de cooperação triangular (Japão-Brasil-Moçambique) sobre o desenvolvimento da agricultura na savana moçambicana, mas esses fundos não aparecem na Tabela 2, embora o seu impacto socioeconômico e ambiental não deva ser negligenciado (Funada, 2013; Garcia et al., 2013).

Outro aspecto que chama a atenção é que a cooperação técnica é responsável por 6,3\% do total do orçamento da CID de 2010, ou seja, 57.770.554 milhões de dólares (IPEA e ABC, 2013, p. 18), do qual a assistência humanitária absorve $17,5 \%$, a cooperação em educação $3,8 \%$, a cooperação científica e tecnológica $2,6 \%$, as operações de manutenção da paz $36 \%$, e as contribuições para organizações multilaterais $33,7 \%$ do orçamento total (Tabe• la 1). A cooperação técnica não é uma prioriN dade em termos de despesa pública, embora \&

\& bilizar expertises de políticas públicas que são oิ avaliadas como boas práticas internacionais.

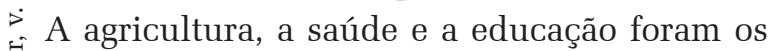
três principais setores da CID do Brasil. De acordo com IPEA e ABC (2010, 2013), países africanos, latino-americanos e caribenhos correspondem aos principais desembolsos no domínio da cooperação técnica, o que confirma tendências históricas desde 1995 (Cabral et al.,
2010; Puente, 2010).

Em nível nacional, a Agência Brasileira de Cooperação (ABC) tem a principal responsabilidade pela coordenação da CID, mas também há unidades de cooperação internacional no âmbito dos ministérios "domésticos" (saúde, educação, cultura, desenvolvimento rural, entre outros); mesmo dentro do Ministério das Relações Exteriores, onde a ABC está localizada, existe uma unidade especial que lida com programas de cooperação de segurança alimentar (Coordenação Geral de Ações Internacionais de Combate à Fome, CGFome). ${ }^{4}$ Pode-se recordar também de iniciativas da CID provenientes da Secretaria Geral da Presidência da República, dos conselhos nacionais de participação (por exemplo, o Conselho Nacional de Segurança Alimentar e Nutricional (CONSEA), bem como a Comissão Permanente para os Assuntos Internacionais (CPAI), vinculada ao Conselho Nacional de Desenvolvimento Rural Sustentável, CONDRAF), estados-federados e municípios. Dessa realidade pode resultar alto grau de diversidade das práticas, mas também de fragmentação da CID brasileira, o que pode produzir problemas de coerência entre diferentes estratégias nacionais e subnacionais da CID e apresentar obstáculos na construção de uma política pública de cooperação no Brasil.

Fornecer cooperação técnica, através de funcionários dos ministérios e organismos públicos, é uma das principais características da CID brasileira. Os funcionários públicos são os principais agentes de implementação da CID brasileira; eles tendem a ser menos caros do que os profissionais nacionais e internacionais do mercado. De um lado, isso contribuiu para impedir o crescimento de uma "indústria da ajuda" no Brasil; por outro, muitas organizações da sociedade civil acabam sendo excluídas dos projetos e programas da CID brasileira, eminentemente interestatal.

${ }^{4}$ A CGFome lida com assistência humanitária, segurança alimentar, desenvolvimento rural e agricultura familiar de pequena escala. Para mais informações sobre a CGFome, veja: http://www.itamaraty.gov.br/o-ministerio/o-ministerio/cgfome-coordenacao-geral-de-acoes-internacionais-decombate-a-fome/ 
Há exceções, como a Viva Rio, a Associação Alfabetização Solidária (AlfaSol) e a Missão Criança, que são exemplos de ONGs atualmente envolvidas em projetos de cooperação educacional e humanitária da ABC. No entanto, várias ONGs brasileiras de direitos (direitos humanos, direitos das mulheres, direito ao desenvolvimento, direito ao meio ambiente, etc.) criticam o governo brasileiro pelo "déficit de participação" (Santos, 2014).

Paradoxalmente, a CID brasileira também pode revelar tensões público-privadas, uma vez que os países onde os projetos de cooperação técnica são mais numerosos também podem ser aqueles onde as empresas transnacionais brasileiras estão presentes. Os investimentos estrangeiros diretos do Brasil em mineração (Vale), infraestrutura e projetos de engenharia civil, como estradas, aeroportos, portos, metrôs, energias, etc. (Odebrecht, Andrade Gutierrez, Camargo Correa, entre outras), prospecção de petróleo (Petrobras), e agronegócio, entre outros setores da economia, têm sido atores-chave das relações entre o Brasil e os países africanos e latino-americanos. Novos setores, como o de biocombustíveis (etanol e biodiesel), têm surgido nos últimos anos, aumentando essas tensões e provocando algumas contradições no discurso e na prática da CSS brasileira (Albuquerque, 2014). Os investimentos seguem lógicas evidentemente diferentes da CID, mas, no terreno, as fronteiras existentes entre as práticas e os agentes envolvidos por um e outro são frequentemente turvas. As estratégias empresariais brasileiras na África e na América Latina podem levantar questões de credibilidade política sobre os modelos econômicos promovidos pelas novas potências, quando comparados com os dos países ocidentais tradicionais. Em que medida as estratégias brasileiras de cooperação Sul-Sul se constituem numa real alternativa de desenvolvimento? O que nos revelam as pesquisas empíricas, entre outras as que conduzimos a fim de produzir este artigo?

\section{PRINCIPAIS CARACTERÍSTICAS DA CID BRASILEIRA NO CAMPO DA EDUCAÇÃO}

De acordo com o banco de dados da ABC disponível na internet, a educação está entre os três setores mais relevantes dos programas de cooperação técnica do Brasil, ao lado de saúde e agricultura. A maioria das atividades de cooperação técnica desenvolvida no setor da educação (CT/ED) está relacionada à formação, capacitação, gestão pública e transferência de tecnologia nas seguintes áreas: educação profissional, projetos de alfabetização de jovens e adultos, educação não formal e educação para pessoas especiais. A CT/ED brasileira inclui uma extensa lista de setores, mas apenas alguns deles podem ser considerados como áreas prioritárias. Realmente, quando se consideram as atividades concluídas e em curso relatadas pela ABC entre 2005 e 2013, a educação ocupa o terceiro lugar entre todas as atividades: agricultura (19,26\%), saúde $(15,4 \%)$, educação $(10,93 \%)$, defesa e cooperação militar (9,14\%), meio ambiente $(6,01 \%)$, desenvolvimento social $(4,47 \%)$ e energia $(4,02 \%)$. Geograficamente, a CT/ED de ABC também está focada em nações em desenvolvimento da América Latina, Caribe e África, bem como do Timor Leste.

Além dos dados sobre a cooperação técnica publicados pela $\mathrm{ABC}$, o primeiro relatório do IPEA/ABC sobre a CID do Brasil (conhecido como COBRADI), publicado em 2010, apresentou cooperação em educação sob a rubrica "Bolsas de estudo para estrangeiros", enquanto que o segundo relatório oficial (que abrange os dados a partir de 2010, e publicado em 2013) estabeleceu um capítulo separado e específico sobre a "cooperação educacional”. Esse capítulo incluiu bolsas de estudo para estrangeiros e programas de intercâmbio internacional dentro da CID/ED do Brasil. A concessão de bolsas para estudantes estrangeiros virem estudar no Brasil é uma prática política histórica, que havia sido lançada em 1950. De acordo com a Divisão de Temas Educacionais do Itamara- 
ty, os principais objetivos da cooperação educacional brasileira são: (i) promover maiores padrões de educação de cidadãos oriundos de outras regiões em desenvolvimento; (ii) promover diálogo no domínio da educação entre jovens brasileiros e estrangeiros; e (iii) divulgar a cultura e a língua brasileira ${ }^{5}$.

Como lembram Pinheiro e Beshara (2012), cultura e educação são consideradas importantes fontes de soft power do Brasil na arena internacional, uma vez que contribuem para o reforço dos laços políticos e econômicos entre o Brasil e os países parceiros. Essa é uma ferramenta tradicionalmente empregada pelas potências centrais, mas igualmente por países como China, Índia, México e África do Sul (Woods, 2008; Zimmermann \& Smith, 2011). De acordo com os dois relatórios de COBRADI (IPEA e ABC, 2010 e 2013), durante o período 2005-2010, o desembolso de bolsas de estudo de ensino superior totalizou o montante aproximado de 174 milhões de dólares (ver Tabela 3). Em média, entre 2005 e 2010, cerca de $7,4 \%$ de toda a CID foi destinada à cooperação em educação. Entre 2009 e 2010, a despesa pública em CID/ED aumentou 40,7\% (IPEA e ABC, 2013, p. 18). Em 2010, o financiamento de bolsas de estudo aumentou e atingiu $34 \mathrm{mi}$ - lhões de dólares. Isso corresponde a mais de 97\% do total das despesas em 2010 dentro da CID/ED brasileira, de acordo com IPEA e ABC (2013). Em 2010, a distribuição geográfica das bolsas de estudo refletiu prioridades similares da política externa. Um percentual em torno de $73 \%$ das bolsas de graduação foi destinado a estudantes dos PALOP, ao passo que $70 \%$ das bolsas de estudo de pós-graduação, a estudantes da América do Sul. O Ministério de Educação do Brasil tende a dar prioridade aos programas de intercâmbio com países que apresentam deficiências em seus sistemas de ensino superior, e também aos países considerados prioritários nas agendas de política externa brasileira. Desde 2004, as estratégias de cooperação internacional da Coordenação de Aperfeiçoamento de Pessoal de Nível Superior (CAPES) têm enfatizado a América Latina e a África (em particular os PALOP).

Historicamente, a CAPES, o CNPq e a Divisão de Assuntos Educacionais do Itamaraty (anteriormente conhecida como Divisão de Cooperação Educacional) têm sido os principais idealizadores e executores de programas de intercâmbio e bolsas de estudo. As agências federais brasileiras também promovem formação profissional, dirigida a profissionais es-

Tabela 3 - Evolução da despesa pública com bolsas de estudo para estrangeiros (2005-2010)

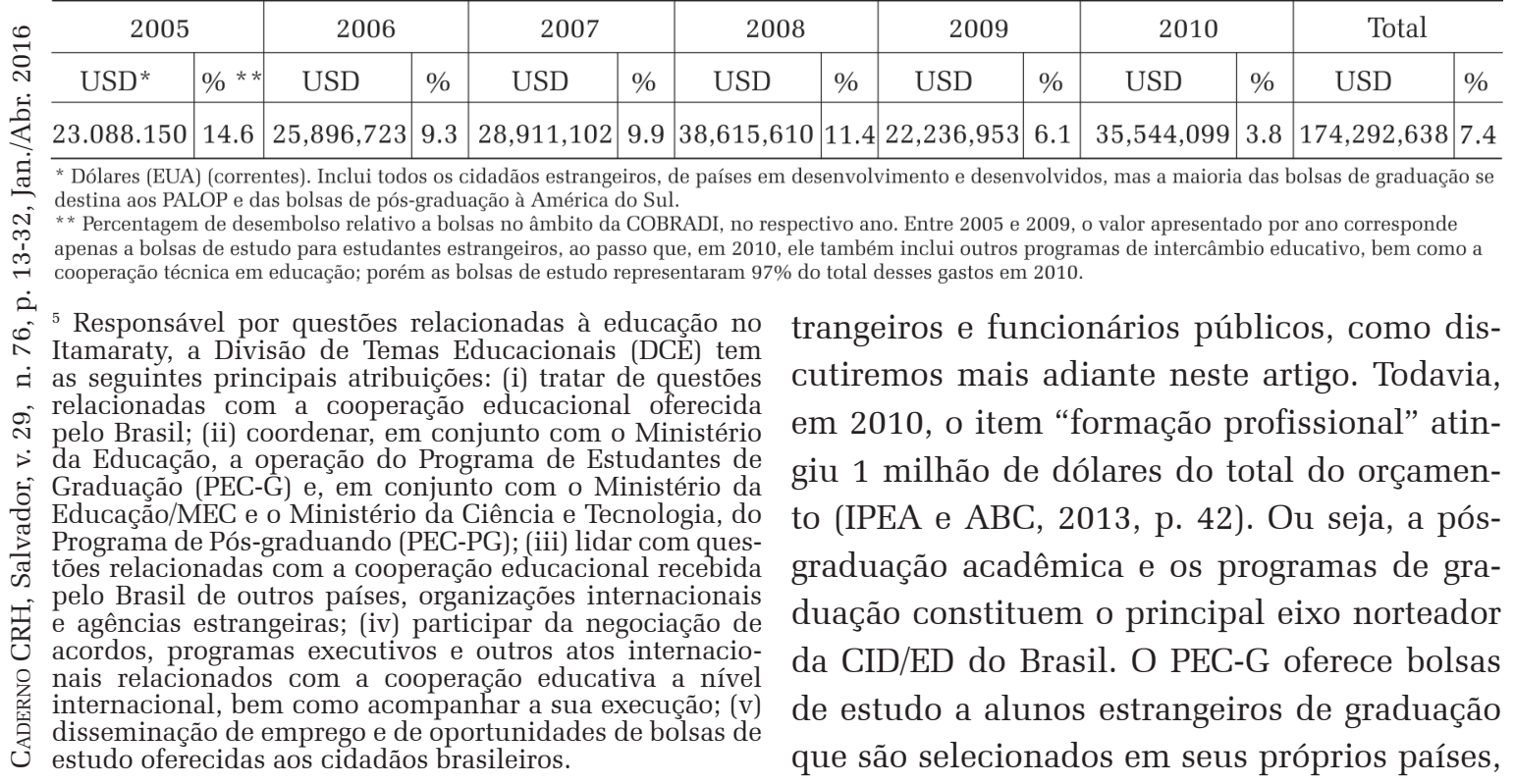


conforme os procedimentos estabelecidos pelo respectivo ministério nacional de educação e da embaixada brasileira local. Já o programa PEC-PG oferece bolsas de estudo para estudantes de graduação estrangeiros para que realizem cursos de mestrado e (ou) doutorado no Brasil. O Quadro 1 resume as principais características de ambos os programas. Em 2010, a maioria dos 1.643 estudantes do PEC-G veio de Cabo Verde (532), Guiné Bissau (436), Angola (147), Paraguai (123), São Tomé e Príncipe (63) e Moçambique (33), enquanto os estudantes do PEC-PG vieram majoritariamente de Colômbia (143), Peru (59), Argentina (36), Timor Leste (26), Cabo Verde (21), Moçambique (17), Angola (13), Guiné Bissau (11), mas nenhum de São Tomé e Príncipe. No caso dos PALOP, é interessante notar que a busca por bolsas de graduação pode refletir a realidade do mercado local em cada um desses países, onde graduados tenderiam a obter trabalho mais facilmente, sem a necessidade de uma pós-graduação - realidade que seria distinta no caso dos países latino-americanos, onde se demanda mão de obra mais especializada. Ademais, vale ressaltar a diferença quantitativa de vagas preenchidas por Guiné-Bissau e Cabo Verde, que, juntos, somam menos de 3 milhões de habitantes, embora enviem mais estudantes do que Angola e Moçambique juntos (ambos com cerca de 50 milhões de habitantes).

Além das bolsas de estudo, o governo brasileiro também desenvolve programas de cooperação triangular com organizações internacionais e ONGs. Um exemplo é o projeto "Jovens Líderes para a Multiplicação de Boas Práticas Socioeducativas”, desenvolvido na Guiné-Bissau em cooperação com a UNES$\mathrm{CO}$, e totalmente financiado pela Agência Brasileira de Cooperação. Na área da educação e de programas não formais de alfabetização de jovens e adultos, pode ser lembrado o projeto desenvolvido pelo Ministério da Educação em parceria com a ONG Associação Alfabetização Solidária (AlfaSol) em Moçambique, Cabo Verde e São Tomé e Príncipe. Os módulos de edu- cação de jovens e adultos foram adaptados aos PALOP e também aplicados em Timor Leste e Guatemala. Contudo, de modo geral, as ONGs brasileiras ainda têm um perfil muito baixo em atividades da CID/ED executadas e financiadas pelo governo brasileiro (Gonçalves, 2011).

Finalmente, ainda merece destaque o campo da educação profissional. Em 2007, 22,4\% do total de desembolsos de ABC tinham sido dedicados à educação profissional, e o Serviço Nacional de Aprendizagem Industrial (SENAI) foi um parceiro fundamental nesse processo. Em termos de número de atividades implementadas e financiadas pela $\mathrm{ABC}$ entre 1995 e 2005, a educação profissional representou $6,11 \%$ do total (Puente, 2010). Criado em 1942, o SENAI é organizado e gerido por empresários industriais, buscando atender a demandas de formação de trabalhadores qualificados para a indústria brasileira. Desde sua criação, 41.700.619 estudantes foram matriculados em escolas do SENAI no Brasil e no exterior. Por meio da cooperação internacional, o SENAI e a ABC exportam os pacotes de ensino e treinamento a países em desenvolvimento em áreas como controle de qualidade de alimentos e embalagens, culinária e gastronomia, sistemas automotivos e de produção, papel e celulose, construção civil, energia, petróleo e fontes de energias renováveis, mineração, entre outros. Inicialmente, na década de 1950, o SENAI recebeu cooperação externa dos países industrializados. Na década de 1960, o modelo de SENAI foi disseminado para os países do Terceiro Mundo por meio da pesquisa Inter American da OIT e o Centro Profissional de Documentação, instituído em 1963. ${ }^{6}$ Desde 1970, ele tem sido ativo na América Latina (Colômbia, Guatemala, Jamaica, Haiti, Paraguai, Peru, Suriname), também em parceria com a Agência Japonesa de Cooperação Internacional. Hoje, ademais, atua nos PALOP e, mais recentemente, em Timor Leste (Gonçalves, 2011).

${ }^{6}$ A Organização Internacional do Trabalho renomeou esse centro em 2007. Agora é o Centro Interamericano para Desenvolvimento do Conhecimento em Formação Profissional (CINTERFOR). 
Em síntese, a CID/ED brasileira é muito diversificada quanto aos atores de concepção e implementação, envolvendo a Agência Brasileira de Cooperação (cooperação técnica), o Ministério da Educação (programa de bolsas, programas de intercâmbio internacional e cooperação técnica), mas também o SENAI (ensino profissional) e, em muito menor escala, algumas ONGs (educação não formal). Essa modalidade da CID conta, principalmente, com fundos públicos e parcerias com empresas privadas e indústrias (como no caso do SENAI). No entanto, a CID/ED brasileira está particularmente concentrada no ensino superior e pode ser considerada fundamentalmente interestatal. Os dois relatórios consolidados sobre a CID/ED brasileira, publicados pelo IPEA e ABC (2010, 2013), focalizam a despesa pública e, em conjunto, representam a quantidade aproximada de 174 milhões de dólares (valores correntes) para o período entre 2005 e 2010. Como IPEA e ABC (2013, p. 42) informam, desde 2010, a cooperação acadêmica alcançou $97 \%$ de todas as despesas oficiais com CID/ED (equivalente a cerca de 35 milhões de dólares), e a cooperação técnica atingiu 3\% (1 milhão de dólares). O governo do Brasil expressa sua intenção de priorizar a formação de elites em sua estratégia de cooperação educacional. Comparando a realidade brasileira com a de outros • países, é óbvio que o Brasil ainda fica atrás em خ termos de gastos globais; no entanto, quando comparação se restringe ao setor da educação superior, a contribuição financeira total do governo brasileiro não é sem relevância, como demonstra a Tabela 4.

\section{A COOPERAÇÃO EDUCACIONAL DO BRASIL COM OS PALOP}

Os PALOP são parceiros fundamentais na agenda de cooperação educacional do Brasil. Além das bolsas de PEC-G e PEC-PG já mencionadas, merecem destaque as atividades de educação à distância e de ensino profissional. O Instituto Rio Branco do Itamaraty também recebe jovens diplomatas dos cinco PALOP para a formação profissional. Organizações da sociedade civil que atuam nesse campo, nos PALOP, são em número mais reduzido, podendo-se incluir a Associação de Apoio ao Programa Alfabetização Solidária (AAPAS), a AlfaSol, a Missão Criança e o Instituto Elos - geralmente concentradas em programas de educação de jovens e adultos. Desde 2003, a Ação Educativa, ONG brasileira com sede em São Paulo, tem estado envolvida em projetos de educação não formal em países da Comunidade dos Países de Língua Portuguesa (CPLP), através da organização de seminários e da criação de um Centro de Referência em Educação de Jovens e Adultos na Cooperação Sul-Sul, em parceria com a UNESCO e a Universidade da Integração Internacional da Lusofonia Afro -Brasileira (UNILAB).

De acordo com dados oficiais sistematizados nas Tabelas 5 e 6, entre 2000 e 2013 havia 5.083 alunos de graduação (PEC-G) provenientes dos PALOP, o que representou, nesse período, $66,2 \%$ de um total de 7,676 estudantes estrangeiros, ao passo que, entre 2000 e 2012, houve 354 estudantes de graduação (PEC-PG) de um número total de 1.880 (18,8\% Tabela 4 - Brasil versus doadores do CAD (2010, dólares EUA)

\begin{tabular}{|c|c|c|}
\hline Países & Cooperação em educação (apenas com países em desenvolvimento) & Apenas ensino superior \\
\hline França & $1,784,330,537$ & $107,487,154$ \\
\hline Portugal & $72,780,487$ & $43,694,871$ \\
\hline Coreia do Sul & $150,122,040$ & $40,499,979$ \\
\hline Espanha & $363,788,964$ & $37,232,677$ \\
\hline Reino Unido & $751,119,399$ & $80,808,790$ \\
\hline EUA & $889,120,487$ & $173,390,935$ \\
\hline Brasil* & $35,382,438$ & $35,229,966$ \\
\hline
\end{tabular}


Tabela 5 - Quantidade de estudantes PEC-G dos PALOP entre 2000 e 2013

\begin{tabular}{l|rrrrrrrrrrrrrrr}
\hline Países & 2000 & 2001 & 2002 & 2003 & 2004 & 2005 & 2006 & 2007 & 2008 & 2009 & 2010 & 2011 & 2012 & 2013 & Total \\
\hline Angola & 3 & 21 & 29 & 23 & 31 & 11 & 31 & 28 & 91 & 68 & 48 & 83 & 61 & 53 & 583 \\
Cabo Verde & 117 & 65 & 227 & 263 & 192 & 230 & 314 & 265 & 381 & 206 & 133 & 76 & 100 & 88 & 2,657 \\
G. Bissau* & 36 & 88 & 111 & 97 & 58 & 186 & 159 & 19 & 133 & 181 & 95 & 55 & 118 & - & 1,336 \\
Moçambique & 12 & 13 & 27 & 21 & 26 & 27 & 13 & 9 & 4 & 4 & 9 & 7 & 6 & 13 & 191 \\
S.T. Príncipe & - & - & 24 & - & 47 & 147 & 35 & 13 & 12 & 4 & 6 & 19 & 5 & 3 & 315 \\
5 PALOP & 168 & 187 & 418 & 404 & 356 & 601 & 552 & 335 & 621 & 463 & 291 & 240 & 290 & 157 & 5,083 \\
Toda a África & 187 & 214 & 451 & 442 & 395 & 650 & 589 & 378 & 784 & 517 & 383 & 378 & 378 & 255 & 6,001 \\
América Latina & 135 & 172 & 140 & 82 & 52 & 130 & 127 & 125 & 118 & 125 & 115 & 84 & 99 & 132 & 1,636 \\
Ásia* & - & - & - & - & - & - & 1 & - & - & - & - & 1 & - & 37 & 39 \\
Todos os países & 322 & 386 & 591 & 524 & 447 & 780 & 717 & 503 & 902 & 642 & 498 & 463 & 477 & 424 & 7,676
\end{tabular}

Fontes: MEC (http://www.dce.mre.gov.br/PEC/G/historico.html).

* Por causa de um golpe de Estado, a Guiné-Bissau foi suspensa do programa em 2013.

Países da Ásia (Timor-Leste, Paquistão e Tailândia) começaram a enviar estudantes em 2006. Todos os países = Toda África + América Latina e Caribe + Ásia

Tabela 6 - Quantidade de estudantes dos PALOP no PEC-PG, entre 2000 e 2012

\begin{tabular}{l|rrrrrrrrrrrr}
\hline Países & 2000 & 2001 & 2002 & 2003 & 2004 & 2005 & 2006 & 2007 & 2008 & 2009 & 2010 & 2011 \\
\hline Angola & 1 & 1 & 6 & 3 & 1 & 2 & 3 & 7 & 5 & 2 & 8 & 10 \\
Cabo Verde & 4 & 4 & 5 & 5 & 6 & 12 & 22 & 6 & 8 & 7 & 15 & 4 \\
G. Bissau & 1 & 1 & 3 & 1 & 1 & 6 & 5 & 2 & 3 & 2 & 6 & 2 \\
Moçambique & 5 & 5 & 9 & 5 & 8 & 12 & 16 & 12 & 9 & 3 & 8 & 21 \\
S.T. Príncipe & - & 1 & - & - & - & 4 & - & - & - & 1 & 1 & 1 \\
5 PALOP & 11 & 12 & 23 & 14 & 16 & 36 & 46 & 27 & 25 & 15 & 38 & 38 \\
Toda a África & 14 & 15 & 25 & 17 & 17 & 40 & 48 & 32 & 28 & 16 & 39 & 39 \\
América Latina & 61 & 60 & 74 & 39 & 52 & 73 & 122 & 127 & 141 & 196 & 143 & 168 \\
Ásia* & 1 & 1 & - & - & 1 & 7 & 1 & 11 & 14 & 18 & 6 & 8 \\
Todos os países & 76 & 76 & 99 & 56 & 70 & 120 & 171 & 170 & 183 & 230 & 188 & 215 \\
\hline
\end{tabular}

Fontes: MEC (http://www.dce.mre.gov.br/PEC/G/historico.html).

* Timor Leste, China e Índia são os três principais países asiáticos.

do número total de alunos de pós-graduação). Guiné-Bissau, 12 de Moçambique, 29 de São Nesse âmbito, já no governo de Lula da Silva, Tomé e Príncipe, 72 de Timor Leste, bem como estabeleceu-se uma nova universidade federal, outros, cerca de 1.058, em educação à distâna fim de promover a cooperação com os PA- cia, provenientes de outros países ${ }^{8}$ (Ullrich \& LOP e demais países da CPLP: a Universidade Carrion, 2013).

Federal da Integração Internacional da Lusofonia Afro-Brasileira (UNILAB). Desde então, a UNILAB tem sido uma universidade-chave para acolher estudantes dos cinco PALOP. Em novembro de 2013, a então Reitora, Nilma Lino Gomes, inaugurou um escritório da rede RIPES (Rede de Instituições Públicas de Educação Superior) em Lisboa, sob os auspícios da $\mathrm{CPLP}^{7}$ com o objetivo de fortalecer as universidades de países de Língua Portuguesa através da mobilidade dos recursos humanos e esforços conjuntos de pesquisa e ensino. Em 2013, a UNILAB tinha 2.698 estudantes: 1.171 do Brasil, 32 de Angola, 50 de Cabo Verde, 181 da

${ }^{7}$ Informações sobre Ripes disponíveis no http://www.cplp. org/Files/Billeder/cplp/Gestor-RIPES-Lisboa.pdf

Além disso, a UNILAB também desempenhou um papel relevante quando foram aplicadas sanções internacionais, definidas no âmbito da CPLP, contra o Governo de GuinéBissau em 2012: uma corrida às bolsas pelos bissau-guineenses foi direcionada à UNILAB, o que nos leva a concluir que o Governo brasileiro adotou posicionamento intermediário entre uma suspensão dos Programas PEC-G e PEC-PG e a manutenção da cooperação com a UNILAB. Nesses dois anos (2012 e 2013) de suspensão dos programas PEC-G e PEC-PG, chegaram, respectivamente, 44 e 78 estudantes à UNILAB.

${ }^{8}$ Site da UNILAB (www.unilab.edu.br) apresenta muitas missões de cooperação e visitas envolvendo os oito países da CPLP. 
Em termos globais, quando se comparam os valores da cooperação educacional do Brasil com os dos programas dos doadores do CAD da OCDE (Tabela 7), em primeiro lugar, impressiona o grau de concentração do programa brasileiro em educação superior: o ensino superior representa mais de 99\% da CID/ED do Brasil com países em desenvolvimento, ao passo que Portugal apresenta 60\%, Coréia do Sul cerca de 27\%, EUA, 19,5\%, Reino Unido, 10,7\%, Espanha, 10,2\% e França, 6\%. Em segundo lugar, quando somente se consideram os projetos em educação superior dos PALOP, ressalta-se a ausência quase total dos EUA e do Reino Unido. Em terceiro lugar, a presença de Portugal e do Brasil nos cinco PALOP chama a atenção, o que pode evidenciar alguma forma de competição na formação de elites africanas. É verdade que esse exercício estatístico preliminar deve ser ampliado, a fim de confirmar ou afastar a hipótese da rivalidade de soft power entre uma exmetrópole e uma potência regional emergente nas relações com os países africanos.
Metodologicamente, a análise fundamenta-se em dados recolhidos a partir de documentos e relatórios oficiais, mas também em entrevistas realizadas em Maputo, em fevereiro de 2014, e anteriormente, em outubro de 2012, e em Bissau, em junho de 2014. A natureza da pesquisa é exploratória, buscando apontar pistas para futuras pesquisas sobre o tema.

Cabo Verde é o número um na lista dos dez principais países com os quais o Brasil coopera por via da $\mathrm{ABC}$, seguido por São Tomé e Príncipe e Moçambique. O programa de cooperação do Brasil com Cabo Verde envolve três tipos de modalidades. A primeira é no campo dos programas de intercâmbio (PEC-G e PEC-PG). Cabo Verde é o país que mais enviou estudantes (com bolsa brasileira ou de outro país) para fazer cursos de graduação no Brasil gratuitamente. É o segundo entre os PALOP quando se consideram ambos os programas: eram 2.657 estudantes de graduação de um número total de 7.676 estudantes estrangeiros (34,6\%), e 112 estudantes de pós-graduação

Tabela 7 - Cooperação em educação com os PALOP

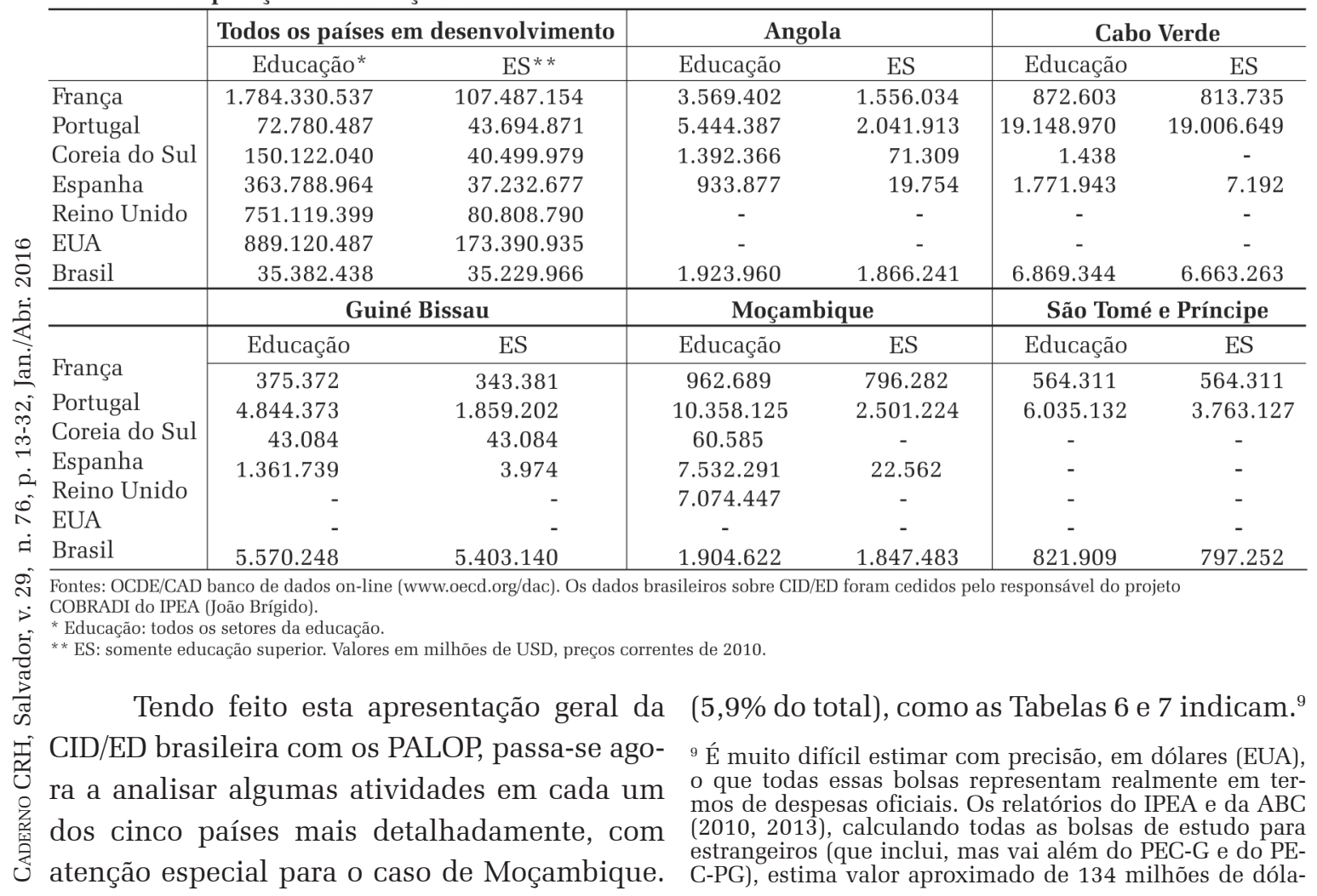


A cooperação técnica com Cabo Verde teve crescimento considerável nos anos 2008, 2009 e 2010, sob o governo de Lula, podendose recordar o programa de cooperação técnica para o desenvolvimento de um mestrado em gestão na Universidade de Cabo Verde (UNICV). Esse programa, totalmente financiado pelo Ministério da Educação, começou em 2004 e envolveu a Universidade Federal do Rio Grande do Sul (UFRGS), além da Universidade Federal do Ceará e a Universidade de Brasília. Entre 2007 e 2009, através de outra parceria de cooperação bilateral, especialistas brasileiros e cabo-verdianos treinaram juntos agentes profissionais e formadores em turismo e hospitalidade. Essa parceria, de 794.000 dólares dos EUA, envolveu a ABC, o escritório federal de Educação Profissional e Tecnológica e o Instituto Federal de Goiás (MEC, 2013, p. 9). Há um terceiro tipo de cooperação entre Brasil, Cabo Verde e organizações multilaterais. Na área específica da alfabetização e educação de jovens e adultos, pode-se mencionar o projeto intitulado "Cooperação em redes internacionais e parcerias inovadoras sobre educação e aprendizagem de adultos", implementado de 2006 a 2011, em parceria com a UNESCO. Ainda entre Cabo Verde, Brasil e PNUD, ressalta-se o centro de formação profissional inaugurado na cidade de Praia, cuja execução ficou a cargo do SENAI - um projeto que chegou a um orçamento de 1.331.000 dólares (EUA) (Brasil) e a contrapartida de 222.000 de Cabo Verde.

No caso de Angola, ressaltam-se os programas PEC-G e PEC-PG, bem como a presença de estudantes angolanos na UNILAB. Além disso, o Ministério do Meio Ambiente iniciou, em 2007, um programa de cooperação em matéria

res para o período 2005-2009 e de 33 milhões em 2010. O cálculo do valor médio de investimento que cada bolsa de estudos para um cidadão estrangeiro representa também depende do curso. Por exemplo, em 2004, para um Bacharel em Matemática, o custo anual foi estimado em cerca de 1.500 dólares (EUA); já para um Engenheiro Agrônomo, o custo anual era de 8.000 dólares, chegando a uma média muito geral dos cursos de graduação no Brasil de aproximadamente 4.200 dólares (EUA) por ano. Estima-se que as despesas gerais com a pós-graduação (mestrado e doutorado) cheguem ao dobro dos custos com a graduação (MAGALHAES et al, 2009; DO AMARAL, 2003). de educação ambiental, com vistas à formação de técnicos do Ministério do Urbanismo e Ambiente de Angola. No nível subnacional, em 2011, Angola e Bahia assinaram um acordo de cooperação em gestão da educação: há atualmente 150 consultores e professores brasileiros que oferecem serviços de consultoria e dão aulas em escolas técnicas angolanas. Desde 2009, Brasil e Angola também cooperam na área da formação rural profissional (MEC, 2013).

No caso de São Tomé e Príncipe, além dos programas PEC-G e PEC-PG e da participação de estudantes na UNILAB, desde 2007 os dois governos cooperam no setor de alimentação escolar. Trata-se de uma tentativa de transferência de uma política pública brasileira (o Programa Nacional de Alimentação Escolar) para São Tomé, por meio de assessoria nas áreas de nutrição escolar, gestão de políticas públicas e controle social. O projeto não se limitou exclusivamente à prestação de serviços de assessoria técnica e treinamento para as cantinas escolares, mas o governo brasileiro também decidiu enviar alimentos para centenas de estudantes do ensino fundamental em São Tomé e Príncipe, aproximadamente 42 mil crianças que frequentam a escola primária. Outra iniciativa é o Programa de Parceria em Alfabetização, envolvendo o Ministério da Educação, a ONG AlfaSol (responsável pela execução) e universidades federais brasileiras. Até 2012, pelo menos 18.491 jovens e adultos de São Tomé e Príncipe tinham frequentado cursos de alfabetização e outros 2.529 haviam participado de cursos de pós-alfabetização. Além disso, 110 professores de São Tomé foram treinados entre 2001 e 2012, a partir de cursos oferecidos no Brasil. No que diz respeito à educação profissional, o SENAI é responsável pela construção de um centro de treinamento em São Tomé, garantindo a formação de professores e doação de materiais educativos. Em 2013, quando da realização da reunião de alto nível dos Ministros da Educação na Bahia, o ministro são-tomense da Educação, Cultura e Formação (Sr. Jorge Lopes Bom Jesus) congratu- 
lou-se com a cooperação do Brasil no desenvolvimento da Universidade Pública de STP, em parceria com o MEC, a Universidade Federal de Minas Gerais e a UNILAB. Na mesma ocasião, o governo africano expressou interesse em projetos de cooperação nas áreas de "formação de professores, sistema de transporte escolar, concepção e divulgação de ferramentas pedagógicas, bem como no reforço do Programa de Alimentação Escolar” (MEC, 2013, p. 11).

Guiné-Bissau também se beneficia dos programas de intercâmbio PEC-G, PEC-PG e UNILAB. O Brasil, por meio do SENAI, construiu um centro de educação profissional em Bissau, onde, desde 2009, cerca de mil e duzentos profissionais foram treinados. Outro centro de treinamento foi desenvolvido para promover a formação de pessoal de segurança, sob os auspícios do Escritório das Nações Unidas sobre Drogas e Crime. É o primeiro centro do gênero fora do Brasil, e essa iniciativa de cooperação triangular recebeu o aporte de três milhões de dólares (EUA) do governo brasileiro entre 2010 e 2013.

\section{O caso de Moçambique}

Brasil e Moçambique têm relações diplomáticas desde novembro de 1975, ano da $\because$ independência de Moçambique. A embaixada సै do Brasil foi inaugurada em Maputo no dia $1^{\mathrm{o}}$ 还

$\therefore$ Brasil e África, mas ainda tendia a privilegiar ơ as relações de amizade entre Brasil e Portugal

$\therefore$ em detrimento dos movimentos de luta anticolonial. A ambivalência do comportamento oficial brasileiro gerou tensões diplomáticas com nações recém-emancipadas em África. Foi somente na década de setenta que a diplomacia brasileira começou a mudar seu perfil em relação aos PALOP, tendo sido um dos primei- ros a reconhecer a soberania dos cinco países a cada momento de declaração das respectivas independências. Com o fim da ditadura militar no Brasil na década de oitenta, o regime democrático foi capaz de desenvolver a sua diplomacia bilateral com os PALOP e multilateral com a CPLP. Essa aproximação gradual entre os PALOP e o Brasil abrange uma ampla gama de programas, e este item busca mapear o campo específico da cooperação educacional.

Existem três grandes fases na evolução da cooperação contemporânea entre Brasil e Moçambique: (a) a partir de independência de Moçambique até os acordos de paz de 1992; (b) os anos noventa, que correspondem ao processo de redemocratização brasileira e à construção das capacidades institucionais moçambicanas, em plena onda neoliberal; (c) o período correspondente ao século XXI, particularmente desde 2003. ${ }^{10}$ A primeira fase é caracterizada pelo estabelecimento de relações diplomáticas, bem como pela assinatura do Acordo-Marco de Cooperação em setembro de 1981, ratificado por ambos os países em junho de 1984 e em vigor desde então. Em junho de 1989, celebraram o Acordo de Cooperação Tecnológica, Técnica e Científica, que, nos artigos I, V, VI e XIII, menciona explicitamente a cooperação educacional. Durante essa primeira fase, como relembra Ana Cambaza ${ }^{11}$ - diretora do Departamento de Educação de Adultos e Alfabetização, no Ministério da Educação de Moçambique - na entrevista que nos concedeu, as principais atividades de cooperação eram a alfabetização e a educação pelo rádio. Funcionários públicos moçambicanos foram treinados e efetuaram visitas a vários Estados dos mais pobres do Brasil, a fim de saber como ${ }^{10}$ A definição de tais fases é nossa, mas é baseada em nos-
sa análise da história das relações bilaterais, entrevistas
realizadas em Maputo e documentos oficiais que nós con-
sultamos (tais como acordos, ajustes, relatórios de missão,
documentos de projeto, relatórios de avaliação) para o
objetivo deste artigo. Os entrevistados são mencionados
apenas no caso de eles terem dado acordo expresso nesse
sentido. Uma lista completa de entrevistas pode ser encon-
trada no final deste artigo.
${ }^{11}$ Todas as entrevistas com autoridades e lideranças mo-
çambicanas foram concedidas em fevereiro de 2014 . 
funcionavam as rádios comunitárias e como desenvolviam seus programas em comunidades rurais. É interessante notar que, atualmente, Moçambique tem um programa chamado Alfa-Rádio, mas com o apoio do governo cubano. Frank António, diretor-geral do Instituto Nacional de Ensino à Distância (INED), confirma a relevância de tais programas comunitários de rádio, que estavam presentes em várias províncias, reafirmando que, entre 1981 e 1984, o então Instituto Nacional Moçambicano para o Desenvolvimento da Educação trabalhou em parceria com o Instituto de Radiodifusão Educativa da Bahia (IRDEB).

Em novembro de 1989, o Centro Cultural Brasil-Moçambique (então Centro de Estudos Brasileiros) foi inaugurado, dando concretude à integração intercultural africano-brasileira. Esse Centro constitui um espaço cultural para a divulgação e a promoção de eventos culturais relacionados a Brasil, Moçambique e outros países africanos. José Aparecido de Oliveira, então ministro da Cultura do Brasil, foi um ator fundamental nesse processo; no entanto, apesar de todos os esforços de Aparecido no sentido de promover a língua portuguesa como patrimônio cultural comum ao Brasil e aos PALOP, Moçambique sofria com a guerra civil, enquanto o Brasil atravessava profundas reformas econômicas em pleno processo de redemocratização.

É importante mencionar que, nos finais da década 1980, à luz de um acordo firmado entre o Ministério de Educação de Moçambique e a Fundação Ford, foi financiado um programa em que 20 estudantes moçambicanos tiveram a oportunidade de frequentar cursos de bacharelado em Ciências Sociais no Instituto de Filosofia e Ciências Sociais (IFCS) da Universidade Federal do Rio de Janeiro (UFRJ). Em 1989, foram efetuadas as primeiras seleções de bolsistas em Moçambique. A partir de 1990, eles iniciaram sua formação no Brasil. Entre 1991 1993, deslocaram-se, em média, cinco bolsistas por ano (Fry, 2001, p. 16). Nessa fase, privilegiavam-se as Ciências Sociais (Antro- pologia, Sociologia e Ciência Política). Dos 20 bolsistas, 13 retornaram imediatamente a Moçambique após a conclusão dos estudos, sendo que sete prosseguiram seus cursos de pós-graduação com apoio do CNPq, e obtiveram, no Brasil, seus títulos de mestre. Posteriormente, com o apoio da CAPES, outros três bolsistas concluíram o doutoramento (Fry, 2001, p. 17). Esses foram, de fato, os primeiros passos da presença de estudantes moçambicanos no nível de ensino superior no Brasil. Não deixa de ser relevante assinalar que, nesse mesmo período e também com o apoio da Fundação Ford, alguns estudantes brasileiros desenvolveram suas pesquisas de campo em Moçambique.

$\mathrm{Na}$ segunda fase, Moçambique assinou seus acordos de paz, e o Brasil tinha avançado nas suas reformas económicas e políticas. A CPLP foi criada em $1996{ }^{12}$ Em 2000, Fernando Henrique Cardoso fez visita oficial a Maputo, onde também participou da Terceira Cúpula da CPLP. Em 2001, o Presidente Joaquim Chissano fez visita oficial ao Brasil, e ambos os presidentes assinaram seis instrumentos de cooperação nas áreas de saúde, educação, política social e segurança pública. No campo específico da cooperação educacional, os acordos diziam respeito à alfabetização, educação de jovens e adultos (em parceria com a AlfaSol), a transferência da política pública da bolsa-escola (em parceria com a ONG Missão Criança), e cooperação técnica. Em agosto do ano seguinte, o Presidente moçambicano participou da IV Cúpula da CPLP em Brasília.

Não obstante a política externa de Fernando Henrique Cardoso não ter enfatizado as relações com os países africanos e os PALOP, em seus dois mandatos, o Brasil aumentou sua

${ }^{12} \mathrm{O}$ primeiro passo para a criação da CPLP foi dado em São Luís (Maranhão, Brasil) em novembro de 1989, por ocasião da primeira reunião dos Chefes de Estado e de Governo dos países de língua portuguesa, a convite do presidente brasileiro José Sarney. Nessa reunião, os representantes do Estado decidiram criar o Instituto Internacional de Língua Portuguesa (IILP). A ideia de uma comunidade reunindo os países de língua portuguesa (geminada com uma herança histórica, pela linguagem comum e uma visão compartilhada do desenvolvimento e da democracia) já estava na agenda. No entanto, só foi implementada em 1996, entre outras, graças ao então embaixador do Brasil em Lisboa, José Aparecido de Oliveira. 
presença nos países da CPLP. O legado da Política Externa Independente dos anos sessenta e do Pragmatismo Responsável dos anos setenta foi instrumental nesse sentido (Vigevani et al., 2003) e, durante a era FHC, a cooperação educacional foi uma das principais portas de entrada para o Brasil em Moçambique. Frank António afirma que, entre 1995 e 1996, Moçambique desenvolveu seus primeiros cursos de formação para professores em parceria com o Brasil: aos cidadãos que tinham pelo menos sete anos de escolaridade formal foi oferecido um curso de formação para se tornarem professores públicos. Esse programa foi encerrado em 2013. No domínio do ensino superior, entre 1993 e 1999, havia 156 cidadãos moçambicanos que se beneficiaram do PEC-G. Como as Tabelas 6 e 7 indicam, havia 52 alunos PEC-G, e outros 19 alunos PEC-PG, entre 2000 e 2002.

Ana Cambaza afirma que, entre $2001 \mathrm{e}$ 2004, os programas de alfabetização eram um impulso importante à cooperação entre Brasil e Moçambique. Com o apoio de universidades brasileiras e da ABC, a AlfaSol (e a AAPAS, seu braço operacional) trouxe metodologias de alfabetização e instrumentos pedagógicos, critérios para a seleção dos formadores baseados em gênero e participação, e também deu apoio ao desenvolvimento de Projeto-Piloto de Alfabetização Nacional de Moçambique. - De acordo com uma avaliação conduzida em 2003, dois dos cinco objetivos do programa AlfaSol (capacitação de gerentes do Departamento de Educação de Adultos e Alfabetização do (ิ) Ministério da Educação e 25\% de execução do

$\stackrel{m}{\rightarrow}$ projeto-piloto) não tinham sido alcançados. Os o principais problemas com a execução dos pro\& jetos diziam respeito à necessária adaptação ơ do material pedagógico para a realidade local, 3 à necessidade de encontrar-se um editor local e à falta de pagamento de alfabetizadores. Três

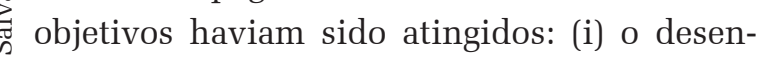
volvimento de 240 grupos de alfabetização em cinco províncias (Cabo Delgado, Gaza, Manica, Maputo e Sofala), envolvendo 1.547 alunos (primeira fase) e 6.160 alunos (segunda fase); (ii) a criação de capacidades de 250 formadores; (iii) a transferência de métodos de avaliação para programas de alfabetização. Na primeira fase, $80,6 \%$ dos alunos eram mulheres; na segunda fase, elas constituíam 73,8\% do total dos beneficiários. ${ }^{13}$ No entanto, o programa AlfaSol enfrentou mais deficiências quando o governo moçambicano decidiu desenvolver um novo currículo de alfabetização: em vista disso, os materiais pedagógicos produzidos no Brasil foram considerados inaptos para as novas necessidades curriculares. ${ }^{14}$ Uma vez que o governo de Moçambique levou vários anos para concluir essa revisão curricular, o programa AlfaSol foi descontinuado. ${ }^{15}$ Apesar de todos esses problemas de ambos os lados, Ana Cambaza enfatizou fortemente, durante a entrevista, que o processo de aprendizagem com os colegas brasileiros foi de grande relevância.

A terceira fase da breve história da cooperação entre Brasil e Moçambique começou em 2003, quando a política externa brasileira passou a enfatizar de forma mais explícita as relações Sul-Sul (Vigevani \& Cepaluni, 2007; Milani, 2013). Em novembro de 2003, durante a visita do presidente Luiz Inácio Lula da Silva a Moçambique, foram assinados onze instrumentos de cooperação técnica. O Presidente Joaquim Chissano respondeu com uma visita oficial ao Brasil em agosto de 2004, quando ambos assinaram um acordo de amortização de 95\% da dívida pública de Moçambique, um montante aproximado de 315 milhões de dólares, con-

${ }^{13}$ Esse relatório de avaliação foi gentilmente disponibilizado por Ana Cambaza.

${ }^{14}$ Não está claro de onde surgiu essa necessidade de um novo currículo de alfabetização, se tinha sido identificada como uma necessidade local genuína, ou como uma condicionalidade decorrente do programa de ajustamento estrutural pelo qual Moçambique estava passando.

${ }^{15}$ A AlfaSol e AAPAS são duas organizações não governamentais criadas pelo Comunidade Solidária, um programa político que funcionava diretamente ligado à Presidência da República e que foi coordenado pela então primeira-dama Ruth Cardoso. O trabalho de ambas as ONGs foi implementado com o apoio do Ministério da Educação do Brasil, mas também está enraizado em parcerias público-privadas (Peroni, 2006). Em 2003, o governo Lula trouxe uma mudança na forma como essas estruturas não governamentais se relacionam com o financiamento público, embora a AlfaSol ainda seja uma parceira de implementação para projetos nacionais e internacionais desenvolvidos pelo governo brasileiro. 
vertido em créditos comerciais concedidos no âmbito do programa de incentivo à exportação do governo do Brasil. Em setembro de 2007, o Presidente Armando Guebuza fez visita oficial ao Brasil como convidado de honra na comemoração de 7 de setembro. À dimensão imaterial de ênfase à solidariedade entre países do Sul também correspondia, na era Lula, uma forte dimensão material da política externa (financiamentos, investimentos, cooperação pública).

No domínio da política de educação, o Brasil deu continuidade ao programa de bolsas de estudo (conhecido em Moçambique como o "Futuro das Crianças") e aumentou o número de bolsas para 400 (100 em 2005, 150 em 2006 e 150 em 2007). A cooperação em educação superior entre Brasil e Moçambique representava aproximadamente 1,85 milhão de dólares (EUA) em 2010 (Tabela 7). No entanto, ainda nessa terceira fase, já no governo de Dilma Rousseff, a cooperação educacional começou a se concentrar mais em educação à distância e ensino técnico aplicado à agricultura, bem como em programas de gestão alimentar e nutricional em ambiente escolar (com o apoio do Fundo Nacional de Desenvolvimento da Educação do MEC). Essa mudança na agenda de cooperação, obviamente, refletiu uma mudança de política na arena doméstica do Brasil, mas também resultou de financiamentos mais vultosos disponíveis em novas áreas. Um exemplo foi o projeto de formação profissional atualmente em execução, intitulado "Curso de algodão - Treinamento e transferência de tecnologia", realizado pela Universidade Federal de Lavras, em parceria com o Itamaraty e o Instituto Brasileiro do Algodão. ${ }^{16}$ Em março de 2014, esse novo curso foi aberto

${ }^{16}$ Em 2010, os governos do Brasil e dos Estados Unidos da América concordaram em criar um fundo com recursos do Commodity Credit Corporation, um corpo dentro do governo americano, como uma solução parcial para o contencioso do algodão na Organização Mundial do Comércio entre os dois governos sobre os subsídios concedidos pelo governo americano aos seus produtores de algodão. Isto levou à criação do Instituto Brasileiro do Algodão, uma associação civil sem fins lucrativos criada em junho de 2010 para gerir esses fundos, com vista ao desenvolvimento e fortalecimento da indústria de algodão do Brasil a nível nacional e através da cooperação internacional. para trinta profissionais dos PALOP com pelo menos curso de graduação na área de Ciências Agrárias. Cada aluno selecionado recebe uma bolsa mensal de cerca de 1.000 dólares (EUA). Os parceiros brasileiros pagam todas as despesas, incluindo bilhetes de ida e volta de avião, seguro de saúde e de vida, alojamento e refeições. Cada edição do curso dura quatro meses. O projeto Universidade Aberta (UA) é uma iniciativa atual e uma das mais importantes da cooperação educacional do Brasil em Moçambique. Oferece cursos de graduação a 690 cidadãos moçambicanos. Em 2013, a UNILAB passou a integrar o comitê de direção do projeto e há quatro outras universidades federais envolvidas: a Universidade Federal de Juiz de Fora, da Universidade Federal de Goiás, a Universidade Federal do Estado do Rio de Janeiro e da Universidade Federal Fluminense. A Universidade Aberta do Brasil desempenha o papel de coordenação. Em Moçambique, os dois parceiros principais são a Universidade Eduardo Mondlane e a Universidade Pedagógica. Por meio desse projeto, professores brasileiros e moçambicanos prepararam, conjuntamente, as ferramentas pedagógicas, a correção dos testes, o acompanhamento dos estudantes nos módulos de ensino, etc. Na já citada reunião de alto nível realizada na Bahia em 2013, o ministro moçambicano da Educação (Sr. Augusto Luís) manifestou interesse em desenvolver projetos de cooperação nas áreas de educação digital e uso pedagógico das tecnologias da informação, nomeadamente no âmbito da expansão da Universidade Aberta do Brasil em Moçambique. Atualmente, o programa privilegia o desenvolvimento de cursos em matemática (Universidade Federal Fluminense do Brasil e Universidade Pedagógica de Moçambique), gestão pública (Universidade Federal de Juiz de Fora e Universidade Eduardo Mondlane), educação infantil (Universidade Federal do Rio de Janeiro e Universidade Pedagógica) e biologia (Universidade Federal de Goiás e Universidade Pedagógica). Em Moçambique, existem cerca de 60.000 professores primários e 8.000 professores do ensino médio - e 31\% de- 
les não possuem diploma universitário. O programa da UA visa a capacitar 4.940 professores e 1.350 gerentes de agências governamentais entre 2012 e 2015. O Brasil apoia Moçambique com infraestrutura de educação à distância, pagamento bolsas de estudo para professores e monitores, e transferência gratuita de toda a tecnologia (MEC, 2013).

É sabido que Moçambique coopera com muitas agências bilaterais e multilaterais no âmbito de relações Norte-Sul. Durante os anos noventa, recebeu cerca de 700 milhões de dólares de ajuda oficial ao desenvolvimento (AOD) por ano e, no século XXI, em 2006, essa média aumentou para 941 milhões de dólares (EUA), 1,71 bilhão em 2011 e 1,48 bilhão em 2012, segundo estatísticas da OCDE. Em contraste com esses montantes, em termos financeiros, a cooperação brasileira é irrelevante, mas seu foco em cooperação técnica, ensino superior e educação à distância tende a ser bem avaliado por gestores nacionais, que salientam seu potencial para o futuro - mas apenas sob certas condições. No caso da educação à distância, há duas condições claras que foram mencionadas ao longo das entrevistas. Em primeiro lugar, os moçambicanos estão acostumados a lidar com as agências do Norte, e cada vez mais procuram controlar o processo de tomada de decisão e definição de prioridades. Frank António $\because$ recorda que, em épocas anteriores, o Brasil N tentou impor seu próprio modelo de educa\&

$\therefore$ das semelhanças que ambos os países em deơ senvolvimento possam compartilhar, há uma

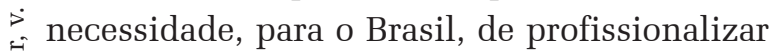
sua política de cooperação educacional e de ajustar suas propostas de políticas para a reaF lidade local moçambicana. Em segundo lugar, Frank António afirmou que há muitos agentes envolvidos no programa Universidade Aberta do Brasil. Cada uma das cinco universidades federais tem uma participação e demanda procedimentos específicos. Isso, muitas vezes, fragmenta os processos de tomada de decisão e acarreta dificuldades na coordenação. É por isso que, desde 2012, duas comissões de coordenação foram criadas, uma em cada um países, o que permitiu a cada lado falar com uma única voz. Esse esforço de coordenação é vital, porque está previsto que o acordo de educação à distância dure até 2019.

\section{CONSIDERAÇÕES FINAIS}

Nos primeiros anos do século XXI, com as mudanças na geopolítica e na geoeconomia global, muitos países do Sul passaram a redefinir seu papel como fornecedores de cooperação internacional para o desenvolvimento. O Brasil não é exceção, e suas práticas de cooperação têm sido reconhecidas por organizações internacionais e consideradas potencialmente úteis para outros países em desenvolvimento. Isso vale igualmente para o campo da cooperação educacional, no qual o governo brasileiro age claramente em pelo menos três dimensões: (i) economicamente, pois a educação se relaciona diretamente com a qualificação de mão de obra de um país, e a cooperação educacional busca construir capacidades; (ii) no plano político, a cooperação educacional é parte de uma agenda positiva de política externa do Brasil, que busca promover relações mais estreitas entre os Estados e as sociedades baseadas em princípios de solidariedade e não intervenção nos outros países em desenvolvimento; (iii) culturalmente, pois a convivência, a aprendizagem e o intercâmbio de experiências podem contribuir para a formação das elites de países em desenvolvimento, o reforço dos laços entre diferentes sociedades e a compreensão mútua de realidades semelhantes, mas também distintas.

É interessante lembrar que a formação de professores brasileiros do ensino fundamental sobre história e cultura africanas é de grande relevância: dez anos após a sanção da 
Lei 10.639 (em 2003), o MEC do Brasil apresentou uma proposta à CPLP, a fim de enviar professores brasileiros para estágio de curto prazo nos PALOP. Esses estágios os beneficiariam com uma imersão educacional no contexto cultural, social e histórico africano (MEC, 2013). Nesse caso, é o Brasil que demanda a cooperação dos PALOP - evidenciando, em alguma medida, a busca por reciprocidade na cooperação. No caso particular dos PALOP, a cooperação em ensino superior também interessa ao Brasil, porque é parte da agenda de internacionalização de suas próprias universidades. Em Moçambique, Frank António lembrou, durante a entrevista, que ter um interesse não é um problema em esquemas de cooperação bilateral, uma vez que esse tem sido sempre o caso em muitos outros formatos da CID. O desafio é organizar o processo de cooperação.

É evidente, diante do exposto neste artigo, que os princípios da política externa brasileira de cooperação Sul-Sul (solidariedade, horizontalidade, não ingerência, respeito à soberania estatal, não uso de condicionalidades políticas relacionadas a direitos humanos e democracia liberal, compartilhamento de experiências e práticas de políticas públicas, etc.) estão enraizados em narrativas oficiais que devem ser analisadas à luz de pesquisas empíricas e com lentes analíticas, fundadas em autonomia acadêmica e isenção científica. Essa premissa é fundamental para se verificar em que medida a cooperação educacional brasileira difere da AOD promovida pelos membros do CAD da OCDE.

As percepções provenientes dos PALOP sobre a cooperação com o Brasil no setor da educação superior e profissional são geralmente positivas. Isso não impede que, ainda hoje, o governo brasileiro tenha dificuldades de coordenação institucional da cooperação brasileira. A ABC é apenas uma entre muitas instituições a intervir na tomada de decisões e na implementação de projetos. O anúncio feito pela presidente Dilma Rousseff em maio de 2013, em Adis Abeba, sobre a criação de uma nova agência não produziu resultados políticos.
Mais do que isso, a crise econômica e política do governo de Dilma Rousseff, desde junho de 2013, tem afetado muito negativamente as estratégias de CID do Brasil. Em 2015, a ABC tem trabalhado na formulação de um projeto de lei que visa a ordenar esse processo, por meio da criação de fundos específicos para a cooperação, de um marco jurídico e de uma carreira específica de agentes da cooperação - aspectos considerados relevantes para que, na celebração dos trinta anos da ABC em 2017, o governo brasileiro apresente à sociedade uma política pública de cooperação para o desenvolvimento com claro desenho institucional, normas de transparência, critérios de avaliação dos resultados que sejam públicos e abertos ao debate.

Finalmente, isso nos leva a outro desafio ainda por ser resolvido: o lugar da participação social na política brasileira de cooperação, em geral, e educacional, em particular. No caso de Moçambique, o Brasil enfatiza a cooperação horizontal e a cooperação interestatal, tendendo a não assegurar participação mais ativa da sociedade civil na concepção ou implementação de projetos, nem na discussão sobre seus resultados de médio e de longo prazo. Entrevistados também apontaram dificuldades em função da descontinuidade dos projetos ou dos orçamentos. No campo da CID, a improvisação é um risco. Isso implica que o governo brasileiro deve enfrentar as questões relacionadas com a falta de capacidades, a ausência de um quadro regulamentar adequado, o financiamento insuficiente, a pouca avaliação dos resultados, bem como os cortes orçamentários constantes. Para futuros programas de cooperação, particularmente no campo da educação à distância, Frank António, de Moçambique, sugere melhorar as fases de diagnóstico e de acompanhamento, bem como estabelecer critérios de avaliação dos projetos: ele sugere que Brasil e Moçambique trabalhem juntos já nessas fases do ciclo de projetos.

Recebido para publicação em 01 de outubro de 2015 Aceiro em 20 de dezembro de 2015

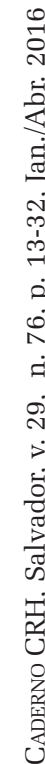




\section{REFERÊNCIAS}

ALBUQUERQUE, R. R. Inserção internacional e energia: a política externa de Lula para Biocombustíveis. 2014. 136 p. Dissertação (Mestrado em Ciência Política) - Programa de Pós-Graduação em Ciência Política da Universidade do Estado do Rio de Janeiro.

AMARAL, N. C. Evolução do custo do aluno das Ifes: eficiência. Avaliação: Revista da Rede de Avaliação Institucional da Educação Superior, v. 9, n. 1, p. 115-125, mar. 2003.

BRAUTIGAM, D. Aid 'with Chinese characteristics': Chinese foreign aid and development finance meet the OECD-DAC aid regime. Journal of International Development, n. 23, p. 752-764, 2011, DOI: 10.1002/jid

CABRAL, L.; WEINSTOCK, J. Brazil: an emerging aid player. Lessons on emerging donors, and South-South and trilateral cooperation. London: Overseas Development Institute (Briefing Paper n. 64), 2010.

CHATUVERDI, S.; FUES, T.; SIDIROPOULOS, E. (Orgs.). Development Cooperation and Emerging Powers: New Partners or Old Patterns? London/N. York: Zed Books, 2012.

CHISHOLM, L.; STEINER-KHAMSI, G. South-South Cooperation in Education and Development. New York/ London: Teachers College Press, 2009.

COMELIAU, C. Les relations Nord-Sud. Paris: La Découverte, 1991.

FRY, P. Moçambique: ensaios. Rio de Janeiro: Editora UFRJ, 2001.

FUNADA, S. Análise do discurso e dos antecedentes do Programa Pró-Savana em Moçambique - enfoque no papel do Japão. Tokyo University of Foreign Studies, 2013.

GARCIA, A. S.; KATO, K.; FONTES, C. A história contada pela caça ou pelo caçador? Perspectivas sobre o Brasil em Angola e Moçambique. PACS, MISEREOR, 2013. Disponivel em http://www.pacs.org.br/files/2013/03/ Relatorio-Africa.pdf.

GONÇALVES, F. C. N. Cooperação Sul-Sul e política externa: um estudo sobre a participação de atores sociais. 2011. 170 p. Dissertação (Mestrado em Relações Internacionais) - Programa de Pós-Graduação em Relações Internacionais da PUC-Rio.

IPEA (Institute de Pesquisa Econômica Aplicada) \& ABC (Agência Brasileira de Cooperação). Cooperação brasileira - para o desenvolvimento internacional: 2010. Brasília: Ipea/ 尺 $\mathrm{ABC}, 2013$.

IPEA \& ABC. Brazilian Cooperation for International Development 2005-2009. Brasília: Ipea: ABC, 2010.

LANCASTER, C. Foreign Aid: diplomacy, development, if domestic politics. Chicago: The University of Chicago î Press, 2007.

¿ MAGAlHAES, E. A.; SILVEIRA, S.; ABRANTES, L.; 0 FERREIRA, M.; WAKIM, V. Custo do ensino de graduação $\wedge$ em instituições federais de ensino superior: o caso da

\& Universidade Federal de Viçosa. Revista de Administração

ô Pública, v. 44, n. 3, p. 637-666, 2010 (http://dx.doi. จ $\mathrm{org} / 10.1590 /$ S0034-76122010000300005).

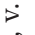

MEC (Brazilian Ministry of Education). Education as a Strategic Bridge for the Brazil-Africa Relationship. Brasília: MEC, 2013

कึ MILANI, Carlos R. S. Aprendendo com a história: críticas İ à experiência da Cooperação Norte-Sul e atuais desafios à Cooperação Sul-Sul. Caderno CRH Salvador: EDUFBA), v. 25, p. 211-231, 2012

Discursos y mitos de la participación social en la cooperación internacional para el desarrollo: una mirada a partir de Brasil. Revista Española de Desarrollo y Cooperación, v. 22, p. 161-182, 2008.

; SUYAMA, B.; LOPES, L. Políticas de Cooperação Internacional para o Desenvolvimento no Norte e no Sul: que lições e desafios para o Brasil? São Paulo: Friedrich Ebert Stiftung, 2013.

CARVALHO, Tassia. Cooperação Sul-Sul e Política Externa: Brasil e China no continente africano. Estudos Internacionais, v. 1, n. 1, p. 11-35, 2013.

NAYLOR, T. Deconstructing Development: the use of power and pity in the international development discourse. International Studies Quarterly, v. 55, n. 1, p. 177-197, 2011.

PANKAJ, A. K. Revisiting Foreign Aid Theories. International Studies, v. 42, n. 2, p. 103-121, 2005.

PERONI, V. Conexões entre o público e o privado no financiamento e gestão da escola pública. EccoS - Revista Científica (São Paulo), v. 8, n. 1, p. 111-132, 2006.

PETITEVILLE, F. La coopération de l'Union Européenne entre Globalisation and Politisation. Revue Française de Science Politique, v. 51, n. 3, p. 431-458, 2001.

PINHEIRO, L.; BESHARA, G. L. Política externa e educação: confluências e perspectivas no marco da integração regional. In: PINHEIRO, L.; MILANI, C. R. S. (Orgs.). Política externa brasileira: as práticas da política e a política das práticas. Rio de Janeiro: Fundação Getúlio Vargas, 2012, p. 149-180.

PUENTE, C. A cooperação técnica horizontal brasileira como instrumento de política externa: a evolução da técnica com países em desenvolvimento - CTPD - no período 1995-2005. Brasília: FUNAG, 2010.

RIST, G. Le développement: histoire d'une croyance occidentale. Paris: Presses de Sciences Po, 1996.

SANTOS, T. Entre o Norte e o Sul: um estudo sobre o papel das organizações da sociedade civil brasileira na cooperação internacional para o desenvolvimento. Tese de Doutorado (Doutorado em Administração) - Programa de Pós-Graduação em Administração da Universidade Federal da Bahia (UFBA).

ULLRICH, D.; CARRION, R. M. A cooperação brasileira na área da educação nos PALOPs no período 2000-2012: principais atores e projetos. $4^{\circ}$ Encontro Nacional da ABRI. Belo Horizonte 2013.

VEEN, M. Ideas, Interests and Foreign Aid. Cambridge: Cabridge University Press, 2011.

VIGEVANI, T. et al. Política Externa no período FHC: a busca de autonomia por integração. Tempo Social, v. 15, n. 2, pp. 31-61, 2003.

VIGEVANI, T.; CEPALUNI, G. A política externa de Lula da Silva: a estratégia da autonomia pela diversificação. Contexto Internacional, v. 29, n. 2, p. 273-335, 2007.

WOODS, N. Whose AID? Whose influence? China, emerging donors and the silent revolution in development assistance. International Affairs, v. 84, n. 6, p. 1205-1211, 2008.

ZIMMERMANN, F.; SMITH, K. More Money, More Actors, More Ideas for Development Co-operation. Journal of International Development, v. 23, n. 5, p. 722-738, 2011.

\section{Websites}

Relatório da missão brasileira na República democrática de São Tomé e Príncipe. Ministério da Educação Fundo Nacional de Desenvolvimento da Educação - FNDE. site: http://www.rebrae.com.br/artigo/sao_tome.pdf 
ALFASOL: http://www.alfabetizacao.org.br/

Cooperação do Serviço Nacional de Aprendizagem Rural (SENAR) em Angola. Site: http://www.senar.org.br/ noticia/cooperacao-do-senar-em-angola-seguira-em-areaespecifica

Celso Amorim inaugura Centro de Formação Profissional de Cabo Verde. INFORPRESS/Agência Cabo-verdiana de notícias, 2013. Site: http://www.inforpress.publ.cv/ sociedade-mlt/5814-celso-amorim-inaugura-centro-deformao-profissional-de-cabo-verde

Curso do algodão: www.oleo.ufla.br/algodao

Ensino a distância: http://eadbrasilmocambique.org/ programa

Embaixada do Brasil em Moçambique: http://maputo. itamaraty.gov.br

CPLP: http://www.cplp.org

IRDEB: https://www.irdeb.ba.gov.br

\section{Lista de entrevistas conduzidas em Maputo em fevereiro de 2014}

Doutora Ana Cambaza: Ministério da Educação, Departamento de Alfabetização e Educação de Adultos, Diretora do Departamento.

Sr. Bruno Alves, Embaixada Brasileira em Maputo, Setor de Educação, diplomata.

Dr. Frank António, Instituto Nacional do Ensino a Distância, Diretor-Geral.

Visita ao Instituto de Bolsas de Estudo, para coleta de dados.

Ministério da Ciência e Tecnologia, Departamento de Cooperação Internacional (Dr. Tonela) e Responsável Brasil (Dr. Policárpio).

Ministério da Educação, Departamento de Cooperação, Responsável Brasil (Dra. Zaida Baule). 


\section{SOUTH-SOUTH COOPERATION IN EDUCATION AND RELATIONS BRAZIL-PALOP}

\author{
Carlos R. S. Milani \\ Francisco Carlos da Conceição \\ Timóteo Saba M'Bunde
}

Studies on North-South and South-South development cooperation have demonstrated that there are distinct types of historical experiences, with multiple domestic actors being involved and thematic agendas being reinforced based on different political motivations, as well as various institutional designs conceived by national governments in order to implement their international development cooperation (IDC) strategies. This paper focuses on Brazil's strategies as a provider of IDC in the field of education (IDC/ED), analysing its general trends, institutional design, agendas and actors, but also presenting an overview of Brazilian IDC/ED in Portuguese-Speaking African Countries (PALOPS), with a case-study on Mozambique, and taking into account the perceptions of beneficiaries.

KEYWORDS: International development cooperation. South-South cooperation. Brazilian foreign policy. Brazil-Africa relations. Portuguese-speaking African countries.

\section{COOPÉRATION SUD-SUD DANS L'ENSEIGNEMENT ET RELATIONS BRÉSIL-PALOP}

\author{
Carlos R. S. Milani \\ Francisco Carlos da Conceição \\ Timóteo Saba M'Bunde
}

Des études sur la coopération internationale au développement (Nord-Sud et SudSud) ont démontré qu'il existe différents types d'expériences historiques, avec de multiples acteurs nationaux étant impliquées et des agendas thématiques fondées sur des motivations politiques différentes, ainsi que des modèles institutionnels conçus par les autorités nationales afin de mettre en œuvre leurs stratégies de coopération internationale au développement (CID). Ce document met l'accent sur les stratégies du Brésil en tant que fournisseur de CID dans le domaine de l'éducation (CID/ED), en analysant ses tendances générales, la conception institutionnelle, des agendas et des acteurs, mais présentant également un aperçu de la CID/ED du Brésil dans les pays africains de langue officielle portugaise (PALOP), avec une étude de cas sur le Mozambique, et ceci en tenant compte des perceptions des bénéficiaires.

Mots CLÉs: Coopération internationale pour le développement. Coopération Sud-Sud. Politique étrangère brésilienne. Relations BrésilAfrique. Pays africains de langue officielle portugaise. antena Rio de Janeiro). Bolsista de produtividade 1-C do CNPq, da FAPERJ (Cientista do Nosso Estado) e da UERJ (Programa Pró-Ciência). Atua nas seguintes linhas de pesquisa: cooperação internacional para o desenvolvimento como agenda de política externa; atores e agendas da política externa brasileira; potências emergentes e política externa em perspectiva comparada. Publicações recentes: Brazil’s human rights foreign policy: domestic politics and international implications. Politikon (Abingdon), v. 42, p. 6791, 2015; Human rights and international politics: between the construction of universalism and the geopolitics of North-South Relations. Artigos (Centro Brasileiro de Relações Internacionais), v. 1, p. 7-26, 2015; Brazil?s foreign policy (2003?2010) towards the IMF: rhetorical and political change during Lula government. Canadian Journal of Latin American and Caribbean Studies, v. 40, p. 116-138, 2015.

Francisco Carlos da Conceição - Doutor em Ciência Política pelo IESP-UERJ. Professor do Departamento de Ciência Política da Universidade Eduardo Mondlane. Suas pesquisas tratam dos efeitos políticos da cooperação internacional para o desenvolvimento em Moçambique.

Timóteo Saba M’Bunde - Doutorando em Ciência Política no IESP-UERJ, com graduação em Relações Internacionais pela Universidade Vila Velha e mestrado em Ciência Política no IESP-UERJ. Atualmente desenvolve pesquisas no campo de Política Externa e Cooperação Internacional para o Desenvolvimento. 